\title{
A IMPRENSA PEDAGÓGICA NO PARÁ EM DIAS DE REPÚBLICA: A REVISTA A ESCOLA E A REVISTA DO ENSINO COMO INSTITUIÇÕES DE FORMAÇÃO (1900-1912)
}

\author{
Darlene Monteiro dos Santos ${ }^{1}$ \\ Maria do Perpétuo Socorro Gomes de Souza Avelino de França ${ }^{2}$
}

\section{RESUMO}

Este artigo analisa como a Revista $A$ Escola e a Revista do Ensino figuraram no cenário cultural e político da educação primária como instituições formadoras de professores no Pará, de 1900 a 1912. Tem como fontes a revista A Escola, com edições de 1900 a 1904 e a Revista do Ensino de 1911 a 1912. Esses impressos estavam sob a tutela do Estado republicano e se tornaram espaços de formação de professores primários. Suas páginas divulgavam orientações para as práticas pedagógicas dos professores e afirmaram protagonismo dos impressos A Escola e Revista do Ensino como mecanismos institucionais e culturais, essenciais para educar, instruir, civilizar, ordenar e moralizar a criança republicana.

Palavras-chave: Imprensa Pedagógica, Educação Primária, Estado Republicano, Instituições de Formação.

${ }^{1}$ Secretaria de Educação do Pará (SEDUC/PA), Belém/PA, Brasil.

${ }^{2}$ Universidade do Estado do Pará (UEPA), Belém/PA, Brasil. 


\section{LA PRENSA PEDAGÓGICA Y EDUCACIÓN EN PARÁ EN DÍAS DE REPÚBLICA: EL PERIÓDICO A ESCOLA Y LA REVISTA DO ENSINO COMO INSTITUCIONES DE FORMACIÓN (1900-1912)}

\section{RESUMEN}

Este estudio analiza como la Revista $A$ Escola y la Revista do Ensino han figurado en el escenario cultural y político de la educación primaria como instituciones formadoras de profesores en Pará, de 1900 a 1912. Posee como fuentes la revista A Escola, con ediciones de 1900 a 1904 y la Revista do Ensino de 1911 a 1912. Estos impresos estaban bajo la tutela del Estado republicano y se tornaron espacios de formación de profesores primarios. Sus páginas, divulgaban orientaciones para las prácticas pedagógicas de los profesores y afirmaron el protagonismo de los impresos A Escola y Revista do Ensino como mecanismos institucionales y culturales, esenciales para educar, instruir, civilizar, ordenar y moralizar al niño republicano.

Palabras clave: Prensa Pedagógica, Educación Primaria, Estado Republicano, Instituciones de Formación.

\section{THE PEDAGOGICAL PRESS IN PARÁ IN REPUBLIC DAYS: THE MAGAZINE THE SCHOOL AND THE MAGAZINE OF TEACHING AS TRAINING INSTITUTIONS (1900-1912)}

\section{ABSTRACT child. \\ LA PRESSE PEDAGOGIQUE ET L'EDUCATION AU PARÁ PENDANT LA REPUBLIQUE: LA REVUE L'ECOLE ET LA REVUE DE L'ENSEIGNEMENTEN TANT QU'INSTITUTIONS DE FORMATION (1900- 1912)}

This paper analyzes how the magazine $A$ Escola and the Revista do Ensino appeared in the cultural and political scene of primary education as teacher training institutions in the state of Pará, from 1900 to 1912. Its sources are the magazine $A$ Escola, with editions from 1900 to 1904 and the Revista do Ensino, with editions of 1911 and 1912. These forms were under the guardianship of the Republican State in Pará and became spaces for the formation of primary teachers. In their pages, they disseminated guidelines for teachers' pedagogical practices. The reviews revealed the protagonism of the A Escola and Revista do Ensino as institutional and cultural mechanisms, essential for educating, civilizing, ordering and moralizing the republican

Keywords: Pedagogical press, Primary Education, Republican State, Training Institutions.

\section{RÉSUMÉ}

Cet article analyse le rôle des revues l'Ecole et la Revue de l'Enseignement dans le scenario culturel et politique de l'éducation primaire en tant qu'institutions formatrices des enseignants 
de l'Etat du Pará dans les années 1900 à 1912. L'article a comme sources, les éditions de l'année 1900 à 1904 de la Revue l'Ecole et les éditions du 1911 à 1912 de la Revue de l'Enseignement. Ces imprimés étaient sous la tutelle de l'Etat républicain et sont devenus des espaces de formation pour les enseignants de l'école primaire. Les contenus donnaient des orientations aux pratiques pédagogiques des enseignants et ont confirmé le protagonisme des ces revues en tant que mécanismes institutionnels et culturels essentiels pour éduquer, instruire, civiliser, ordonner et moraliser le enfant républicain.

Mots-clés: Presse pédagogique, Education primaire, Etat républicain, Institutions de formations. 


\section{INTRODUÇÃO}

Se sois verdadeiro republicano, cuidai e cuidai sempre da educação do povo: ignorância e República são ideias que se repelem.

A Escola, 1900.

As duas primeiras décadas do século XX foram marcadas no estado do Pará por discursos de homens das letras e das ciências sobre a necessidade imperiosa de se investir na educação da população. Acreditava-se que somente por meio da educação se atingiria o tão desejável progresso e civilização.

A epígrafe acima, escrita pelo editorial da revista $A$ Escola, edição de $\mathrm{n}^{\mathrm{o}}$ 3 de 1900, revela o "cuidado" e, ao mesmo tempo, o temor que o regime republicano tinha em relação às altas taxas de analfabetismo que assolavam o estado do Pará. Combater o analfabetismo se apresentava como uma das metas dos republicanos. Consideravam que a República não poderia conviver com a ignorância. Para tanto, era necessário criar estratégias que pudessem minimizar essa situação.

Esse foi o cenário propício para que a imprensa pedagógica pudesse atuar como propagadora do discurso do Estado sobre educação para a construção da ordem republicana.

Este estudo é de natureza documental e tem por objetivo analisar como a revista $A$ Escola e a Revista do Ensino figuraram no cenário cultural e político da educação primária como instituições formadoras de professores no estado do Pará, no período de 1900 a 1912. As edições da revista $A$ Escola compreendem os anos de 1900 a 1904 e da Revista do Ensino, os anos de 1911 a 1912.

Discutir sobre a importância da imprensa de pedagógica no campo da História da Educação, em especial na Amazônia, significa compreendê-la como fonte singular de informações sobre o cotidiano do trabalho pedagógico e das práticas sociais existentes na escola, significa ver a escola por dentro, adentrando em suas particularidades. 
A tomada de impressos como fontes para pesquisas em educação se coaduna com as perspectivas evidenciadas por Bastos (2002), ao declarar que os estudos baseados na imprensa pedagógica "possibilitam avaliar a política das organizações, as preocupações sociais, os antagonismos e as filiações ideológicas, as práticas educativas e escolares”. (BASTOS, 2002, p. 173). Já para Nóvoa, Bandeira, Paulo e Teixeira (2002, p. 13), a imprensa se apresenta como um corpus de extrema importância para a História da Educação, pois possibilita compreender “ $[. .$.$] as dificuldades de articulação entre a teoria e prática: o$ senso comum que perpassa as páginas dos jornais e das revistas ilustra uma das qualidades principais de um discurso educativo [...]".

Para Fernandes (2008, p. 22), as revistas utilizadas no ensino tinham a função não apenas de fazer circular ideias, mas, também de produzir saberes, o que lhes garantiram o poder de institucionalizar o que era produzido no campo pedagógico. Para a autora, a tomada de revistas como Instituições emergem os processos de estruturação do próprio campo pedagógico. Para essa autora a imprensa pedagógica são espaços nos quais são postos em jogo os mais diversos interesses e, ao mesmo tempo, onde disputas se concentram em prol dos discursos que produzem e, por que não dizer, dos perfis que pretende formar.

As práticas retratadas pelas revistas em análise, são pensadas nesse texto, como práticas discursivas, dotadas de complexidades múltiplas e diferenciadas, capazes de construir o mundo como representações. As práticas para (CHARTIER, 2002, p. 28), atuam como produtoras de "ordenamento, de afirmação de distâncias, de divisões; a partir disso, o reconhecimento das práticas de apropriação cultural como formas diferenciadas de interpretação".

Fundamentado nas discussões de Chartier (1991 e 2002), este estudo busca penetrar as nuanças e tensões que constituíram a materialidade e a circularidade das revistas pedagógicas no ensino do Pará. Assim, parte das novas perspectivas de se pensar as práticas e o mundo, da forma como se constituem, assim corrobora com as observações Chartier, ao destacar que: 
(...) as novas perspectivas abertas para pensar outros modos de articulação entre as obras ou as práticas e o mundo social, sensíveis ao mesmo tempo à pluralidade das clivagens que atravessam uma sociedade e à diversidade dos empregos de materiais ou de códigos partilhados. (CHARTIER, 1991, p. 177).

Sobre isso, o pesquisador em história cultural deve se colocar atento para a cultura moldada pela política, pela economia e pela sociedade. A história cultural procura olhar para o momento histórico atentando para os aspectos culturais e sociais, que traduzem o cotidiano dos sujeitos que dele fazem parte.

\section{A IMPRENSA PEDAGÓGICA NO PARÁ REPUBLICANO}

O regime republicano surge em um contexto no qual grande parte da população vivia em condições insalubres e de desconforto social. A República trazia para o seio da sociedade a imagem de que a prosperidade social seria alcançada por meio do mundo civilizado. Sobre essa questão, Sevcenko (2003) aponta que "o progresso significava somente uma coisa: alinhar-se com os padrões e o ritmo de desdobramento da economia europeia, onde "nas indústrias e no comércio o progresso do século foi assombroso, e a rapidez desse progresso miraculosa [...]”. (SEVCENKO, 2003, p. 41).

O progresso propagado pelo novo regime político era a prioridade a ser alcançada de norte a sul do país. As representações criadas sobre o mundo civilizado tinham como fundamento a ciência, o uso de máquinas na indústria, considerados como mecanismos civilizatórios, guiados pelos padrões mundiais.

O final do século XIX e o início do século XX foram marcados no Pará ainda pelo que foi a Belle Époque3. Nesse contexto, o Estado passou a assumir a

\footnotetext{
3 Para Coelho (2011), a Idade de Ouro espelhava o progresso e a civilização, traduziu a cultura urbana de uma burguesia contemporânea que buscava atrelar-se aos padrões europeus, a exemplo da Paris do final do século XIX e início do século XX. Para esse autor, esse período demarcou um processo de profundas transformações culturais, sociais, políticas, materiais e
} 
função de agente patrocinador da modernização, levando a capital paraense a um desenvolvimento urbano acelerado. Sobre o progresso no estado, Sarges (2010) acentua que:

O desenvolvimento urbano que se gestava há algum tempo acelerou-se com a implantação da República que, enfatizando a descentralização, deu maior autonomia à aplicação dos impostos, além de conceber ao Estado maior participação da renda concernente à exportação da borracha. Esse momento de transformação pela qual passou a Amazônia, especificamente Belém, coincidiu com a modernidade surgida em Paris e Viena. (SARGES, 2010, p. 150).

Nas palavras da autora, a modernidade em Belém traduzia-se no progresso em sintonia com o que vinha acontecendo na Europa. A modernidade ofuscava principalmente as razões econômicas que motivaram a difusão das forças modernas na capital, não demonstrando preocupação com as necessidades básicas da população.

É oportuno destacar que a intenção de transformar a cidade não se iniciou com a República, mas, desde o ano de 1880, a capital paraense já apresentava sinais de desenvolvimento urbano, bem como da internacionalização de mercados. O Estado almejava que a cidade se desenvolvesse primando por um espaço limpo, disciplinado e ordenado. No entanto, teve que empreender esforços para replanejar os padrões de conduta, com a criação de um novo sistema de regulação social na capital, o que resultou na criação de um código de posturas para a cidade (SARGES, 2010).

O progresso era a grande obsessão do regime republicano, a burguesia em ascensão lançava seus esforços para a formação de uma nova imagem urbana, com a construção de avenidas, praças, jardins, palacetes e monumentos, tudo feito com materiais vindos do continente europeu. Esse novo espaço público trazia novos perfis de vida urbana que exigiam novos padrões de

mentais, o que se desenvolveu em meio à cultura burguesa que buscou firmar-se mediante a hegemonia do capitalismo industrial, que de certa forma buscou construir a imagem de um homem histórico, formado pelos pilares da ciência, fruto dos processos civilizatórios mundiais. 
comportamento para a vida social (SEVCENKO, 2003).

No Pará, segundo Sarges (2010), a preocupação com as transformações urbanísticas e culturais mais significativas ocorreram entre os anos de 1897 e 1910, momento em que a capital paraense era administrada pelo intendente municipal Antônio Lemos. As razões pelas quais essas transformações se deram justificaram-se pelo momento de consolidação do novo regime, pelo apogeu da borracha no mercado internacional e, finalmente, por Antônio Lemos representar em sua administração municipal o período de modificações estéticas da cidade.

O sentimento de luta contra a ignorância, espécie de trevas vivenciadas pela população, significava uma luta contra o atraso social que acometia grande parte da população. A principal função do poder público era zelar pelo bemestar social, combatendo os maus hábitos de uma população mergulhada na insalubridade. A saúde, saneamento e vida urbana foram os focos da administração pública para o aculturamento urbano da cidade de Belém.

No Pará, a República trouxe em seu bojo a criação de uma moral educadora, que, para Sarges (2010), se estabeleceu enquanto postura reguladora do Estado e via, na população, o seu suporte para a concretização de ações para regular e, ao mesmo tempo, implementar um controle rigoroso dos comportamentos daqueles que habitavam a capital e que, de alguma forma, precisavam se submeter ao Estado.

O padrão de sociedade moderna no Pará colocou o homem na condição de sujeito da cidade, precisando, então, de atitudes policiadas, condizentes com os códigos de comportamentos, que nada mais eram que mecanismos de alinhamento de condutas socialmente aceitas e que, segundo Coelho (2002, p. 18), "reafirmavam valores que a cultura urbana plasmara como inventário social".

A educação, nesse cenário, era a porta-voz do ideário político, de espaço de refinamento das boas condutas e disseminadora das doutrinas republicanas 
concebidas à luz do positivismo, pontos que representavam o progresso tanto político quanto moral.

Foi nesse cenário de efervescência política e social que a imprensa se inseriu no contexto de implementação da República no Pará, liderada por homens de engajamento político e grande influência no meio educacional. A imprensa paraense se assentou como suporte político e social para ecoar os ideais republicanos.

Para Sevcenko (2003), o engajamento político tornou-se "a condição ética do homem das letras" (SEVCENKO, 2003, p. 97). Os esforços desses homens canalizavam para o modo de vida da sociedade brasileira aos moldes europeus. Para eles, era preciso modernizar a nação e integrá-la ao perfil internacional em aspetos culturais e materiais. Portanto, as produções desses homens eram a possiblidade de interferir na ordem social, logo, reformas que instituíssem a abolição, a democracia e a República eram necessárias e indispensáveis. Para tanto, Sevcenko (2003) esclarece que:

Os tópicos que esses intelectuais enfatizavam como as principais exigências da realidade brasileira eram: a atualização da sociedade com o modo de vida promanado da Europa; a modernização das estruturas da nação, com a sua devida integração na grande unidade internacional; e a elevação do nível cultural e material da população. Os caminhos para se alcançar esses horizontes seriam a aceleração da atividade nacional, a liberalização das iniciativas - soltas ao sabor da ação corretiva da concorrência - e a democratização, entendida como a ampliação da participação política [...]. (SEVCENKO, 2003, p. 97).

Geraldo Coelho (2011), ao escrever o artigo "Na Belém da Belle Époque da borracha (1890-1910): dirigindo olhares", destaca a importância da imprensa paraense para a belle époque. Os jornais, como a Província do Pará e Folha do Norte, circulavam a serviço do Estado e repercutiam o caminho da sociedade urbana por meio de crônicas. Esses jornais circularam no Estado desde os anos finais do século XIX e estavam entre os poucos com técnicas avançadas de impressão. 
As páginas desses jornais procuravam reproduzir os discursos da civilidade produzida pela belle époque, esses discursos tinham a função de enaltecer a vida cotidiana na capital urbanizada e de um primado padrão higienista. Esse dia a dia da sociedade moderna paraense tinha como cenário os cafés, teatros, lojas, lugares que estampavam o panorama do novo perfil social. Como explica Coelho (2011), “[...] A imprensa periódica de Belém da época, e mais os jornais de agremiações e de associações profissionais inventariavam, por assim dizer, os lugares, as formas e os sujeitos que emprestavam uma dada visibilidade à belle époque de Belém”. (COELHO, 2011, p. 151).

Para esse autor, a belle époque trouxe a imagem metafórica de Belém como cidade organizada para o progresso e civilização, era a Belém de Antônio Lemos, da grande economia extrativista, submetida a ações de disciplina e segregação social, tudo sob a justificativa do cultivo da imagem de civilidade. Os intelectuais da época procuravam romper com esse estereótipo atrelado apenas ao valor de sua economia, lutavam para resgatar a imagem cultural e intelectual da capital paraense. Coelho (2011) ainda pontua que "Para além das realidades materiais e políticas da belle époque da borracha, há registros narrativos da Belém do látex que procuram recuperar e dialogar com o epicentro da cultura letrada e mundana da então capital do Pará”. (COELHO, 2011, p. 152).

Esses intelectuais tomavam para si a missão de recuperar a imagem que traria novos ares para a sociedade intelectual da época, homens, como Humberto Campos, Theodoro Rodrigues, Eustáquio de Azevedo, Paulinho de Brito e João Lúcio de Azevedo, estavam entre aqueles que faziam de suas produções, traduzidas em crônicas e artigos, espelhos para a exaltação do momento social que viviam.

Esse foi o cenário propício para que esses homens viessem a alcançar um espaço privilegiado na imprensa paraense, não bastava apenas que suas ideias fossem divulgadas para uma parte da sociedade, era necessário ir mais além. O resgate da imagem de cidade letrada deveria surgir nas bases, seria então a educação seu pilar de sustentação, a educação seria o meio de 
manutenção dessa imagem.

O contexto de recuperação da imagem letrada da capital do Pará surge no final do século XIX e início do século XX. Além dos jornais, um considerável número de revistas, entre elas as pedagógicas, se colocavam como veículo de ação intelectual desses homens. A educação seria a porta de entrada para a sonhada regeneração social, logo por meio da iniciativa de intelectuais organizados em associações culturais em seus mais variados campos, como comércio, música, artes, agremiações e sociedades, suas ideias se propagariam.

As duas primeiras décadas da República no Pará foram decisivas para que a imprensa paraense divulgasse os discursos de regeneração social para as camadas populares, logo, os jornais e os impressos foram decisivos para o crescimento e conquista de um mercado de um público leitor que consumia diariamente o que a imprensa produzia. Portanto, a opinião pública era formada por esses intelectuais que detinham o poder de ação social (COELHO, 2011).

Na capital paraense, esse novo cenário propiciou o desenvolvimento de um novo jornalismo, bem como uma nova produção literária, que marcou a área cultural da cidade e repercutiu em um novo cenário para que a imprensa adotasse novas técnicas de impressão e edição, o que tornou possível o acesso das camadas alfabetizadas aos materiais impressos.

Na esfera social, essa nova forma de conceber a imprensa e a literatura trouxe, segundo Sevcenko (2003), novos olhares e abordagens para a vida na cidade. As prosas, os romances e as produções literárias foram responsáveis pelo sonho da vida moderna e civilizada, a exemplo da vida em Paris, vida consumida pela leitura, roupas e adereços, tudo acessível com facilidades estabelecidas pelas viagens ao continente europeu. Sobre esse ponto, Coelho (2011) destaca:

Esse aforismo - civiliza-se - pretensamente histórico atravessou décadas do pensamento social brasileiro, da mesma forma como alimentou, no país, um forte imaginário acerca de um progresso e de 
uma civilização que aqui se estabeleceram na condição de universais. $\mathrm{O}$ natural pendor dos nossos homens de letras e de nossos artistas teria conseguido produzir, em solo cultural tão diversificado, a ambiência social e mental de cidades como Paris, Viena, Lisboa, São Petersburgo, vitrines das proclamadas, e assim cultuadas, conquistas do Progresso e da Civilização. (COELHO, 2011, p. 146).

Muitos desses homens atuavam como críticos culturais e viam na imprensa pedagógica um meio de propagarem a ideia de que o país vivia uma crise moral e intelectual que precisava ser combatida. Sobre isso, Bastos (2002) aponta que "a criação de periódicos pedagógicos pode ser explicada tanto por fenômenos de ordem propriamente educativa, como por fatos de ordem social ou de ordem política”. (BASTOS, 2002, p. 174).

Os impressos pedagógicos A Escola e a Revista do Ensino assumiram o duplo papel no estado, tinham o propósito político e educacional, ao destacarem, em suas seções, comentários acerca da vida política estadual e nacional, ater-se às questões relativas à economia e à administração do Estado. Neles valorizavam textos doutrinários 4 e traduções de textos de clássicos europeus, como Voltaire, Rousseau, Montesquieu e os estudos de Charles Darwin e Augusto Comte, entre outros.

O Cônego Pinheiro foi um dos intelectuais que mais teve visibilidade no impresso $A$ Escola, ao discutir temas relacionados à educação e ao ensino no Pará, na seção "Doutrina”, nos anos de 1903 e 1904, nas edições de no 42 de 1903 e de $n^{0} 46$ de 1904. Nos seus artigos, a educação aparece integrada à ciência, à moral, à civilização, à estética, às leis, à família, aos governos e, principalmente, à consciência pública. Para ele, “[...] a educação é um complexo de virtudes morais, de qualidades especiais e distintas, que formam o mais belo ornamento do homem [...]” (CÔNEGO PINHEIRO, 1904, p. 119). Em 1903, esse pensador apontava, no artigo "Educação", publicado na edição de $n^{0} 42$ da revista $A$ Escola, que a educação necessitava preocupar-se com a mocidade,

\footnotetext{
4 Os "Textos Doutrinários" se referiam às discussões de temas como pátria, moral, civismo, família, heróis pátrios, entre outros assuntos.
} 
valorizando aqueles que possuíam o saber clássico, como os pensadores e publicistas.

Para Coelho (2008, p.138), a Revista Escola e a Revista do Ensino tinham por finalidade aprimorar a educação no Estado do Pará e propagar, em nível regional e nacional, o avanço “alcançado na área educacional”.

De acordo com Costa (2011, p. 19), o papel do professor no processo de implementação do projeto educacional republicano era evidente e sua formação e atuação pedagógica constituíam pontos chave nesse processo, o que, para essa autora, revela o lugar da revista $A$ Escola como elemento para instrumentalizar os professores "por meio da introdução do conjunto de leis, de temas, de métodos educativos e dos comportamentos almejados” daquele que seria o centro da transformação do campo educacional paraense.

A imprensa pedagógica paraense revela-se como lócus privilegiado para difundir ideias cívicas e preceitos liberais como constituição do pacto social. É certo afirmar que o discurso liberal, de certa forma, traduzia um aspecto civilizatório, fator essencial para a civilidade social, tendo como ponto de partida a valorização da instrução para a formação do cidadão. Esse movimento foi importante para solidificar as relações entre sociedade e Estado.

\section{AS REVISTAS A ESCOLA E REVISTA DO ENSINO: A INSTRUÇÃO DE CIDADÃOS}

O regime republicano trouxe certa efervescência aos pensamentos de intelectuais, imprensa e homens políticos que disseminavam a visão de que o Estado deveria ampliar sua atuação sobre a sociedade, assim como sobre todo o território nacional. Essas ideias refletiam percepções e críticas permeadas de novas posturas e condutas advindas com a República, algo que demarcou um novo enquadramento social, dotado de novos valores.

Esse grupo se colocou como responsável pelo novo cenário político, 
econômico e social da nação. Homens, como Tobias Barreto, Clóvis Bevilacqua, Artur Orlando, Araripe Junior, Capistrano de Abreu, Silvio Romero e Graça Aranha, tiveram considerável expressão nacional. Esse último publicou o conto "Malazarte", obra popular, inspirado nas obras do literário Victor Hugo, na imprensa periódica pedagógica no Pará, na Revista do Ensino de nº 5, de 1912.

Destaca-se, também, nesse grupo de intelectuais, Araripe Junior, que, na revista $A$ Escola edição de n ${ }^{0} 45$ de 1904, apresenta uma discussão sobre como deve ser pensada a educação nacional. Na mesma edição, Silvio Romero, discute o ensino público, destacando que a educação deveria unir-se aos objetivos nacionais, defendendo a ideia de uma educação nacional integrada.

Para Sevcenko (2003), esse grupo de intelectuais, de forma alguma, pretendia condenar o Brasil a uma imitação europeia, pretendia sim mostrar a força do patriotismo tão necessário, que traria a claridade e dignidade nacional, forjada, é claro, pelos ideais franceses.

Essa geração de intelectuais trouxe um certo utilitarismo intelectual, na medida em que toda a produção intelectual só teria valor se fosse destinada para a mudança social. Mediante isso, esses homens se colocavam como representantes dos novos ideários e, revelando o espírito da época, diziam ser a sobrevivência do país. Até Tobias Barreto chegou a declarar que no Brasil se tinha um Estado, mas não uma nação, logo cabia à imprensa desenvolver e propiciar esse desenvolvimento (SEVCENKO, 2003).

Para esses homens, o Brasil necessitava de uma ação reformadora que se desdobrasse para a reconstrução da nação e remodelasse o Estado, por meio da modernização das estruturas sociais e políticas. Esses intelectuais atuavam como catalisadores dos processos históricos, diante da grande transformação social, econômica e cultural vivenciada pelo Brasil e, de alguma maneira, contribuíram para o novo cenário nacional.

Diante desse quadro, no Pará, muitos desses intelectuais se apropriaram da revista $A$ Escola e da Revista do Ensino para tornarem 
realidade, por meio da educação, a ação reformadora almejada. Esses impressos pedagógicos circulavam sob a tutela do estado republicano, os textos por eles publicados eram previamente examinados pelo conselho editorial, que deliberava sobre a publicação, com a aceitação ou não do que seria veiculado.

Nessa realidade, a revista $A$ Escola foi lançada no dia 30 de abril de 1900 em Belém, pela Secretaria do Estado do Interior, Justiça e Instrução Pública, tendo como idealizador o Sr. Virgílio Cardoso de Oliveira, Diretor Geral da Instrução Pública do Estado. Entre seus principais redatores estavam Vilhena Alves, Arthur Vianna, Lira Castro, Octávio Pires, José Veríssimo e outros. Sua publicação já era sinalizada no Art. 6 do Decreto de no 625 de 2 de janeiro de 1899, que deu nova organização ao ensino primário no Estado.

Esse impresso pedagógico tinha entre seus principais leitores, o professorado primário do Pará e sua assinatura foi declarada obrigatória por meio do decreto de $\mathrm{n}^{\circ} 850$ de 30 de abril de 1900 , sob a administração do governador José Paes de Carvalho. Como se observa nos artigos do decreto de $n^{\circ} 850$ de 1900:

Art. $\mathbf{1}^{\mathrm{o}}$. É obrigatório para o professorado primário do Estado a assinatura da revista do ensino "A Escola", publicada sob a direção e redação do Diretor Geral da Instrução Pública.

Art. $2^{0}$. A contribuição da assinatura anual para cada professor será de seis mil réis, ouro, pagos em doze prestações mensais por meio de desconto nos vencimentos.

Art. $3^{0}$ _. O Tesouro Público do Estado por ocasião do pagamento dos vencimentos mensais dos professores descontará a cada um a importância de quinhentos réis, ouro, que será escriturada em caixa especial como rendimentos da revista. (PARÁ, ATOS E DECISÕES, DECRETO No 850, 1900, p. 192).

$O$ decreto $\mathrm{N}^{\circ} 850$ de 1900 estabelece a obrigatoriedade da assinatura da revista $A$ Escola pelos professores do Pará. Essa obrigatoriedade custava aos professores o valor anual de 6 mil contos de réis, divididos em 12 parcelas de 500 contos de réis, que somavam o valor anual de 6000 mil contos de réis. Essa 
arrecadação ficava a cargo do Tesouro Público do Estado, instituição responsável pela administração do rendimento obtido para a manutenção da revista A Escola.

Sobre a obrigatoriedade na edição de $\mathrm{n}^{\circ} 1$ de 1900 da revista $A$ Escola, o Diretor da Instrução Pública do Pará, Virgílio Cardoso de Oliveira, ao discursar para o Conselho Superior de Educação Pública em 30 de setembro de 1899, destacou a importância de uma revista que se destinasse a orientação de professores "[...] a discussão proveitosa e inteligente sobre o assumpto de instrução, levando ao mesmo tempo, a todos o nosso professorado, que eu penso de ser obrigado a assinar essa revista[...]" (OLIVEIRA, A ESCOLA, 1900, p. 17).

Os professores da educação primária do Pará, assinantes da revista, eram os principais mantenedores do impresso, uma vez que o valor destinado à assinatura era retido no seu vencimento mensal, garantindo o suporte financeiro, a circularidade da revista e a divulgação das ações do governo paraense na educação. Essa ação do Estado foi capaz, ainda, de garantir, não apenas fidelizar leitores, propagadores dos ideais republicanistas, e, também, assegurar a submissão dos professores ao ideário do novo regime, como leitores sujeitos às políticas e orientações para a educação no Estado. A criação da revista $A$ Escola, pela administração pública da época custou um alto preço aos professores, que além de terem parte dos vencimentos retidos em fonte, tinham ainda a sua autonomia intelectual e profissional sob as rédeas do Estado.

Os discursos embutidos no próprio decreto deixavam claro o teor das políticas direcionadas aos professores do Pará. Essas políticas eram modeladoras, reguladoras e direcionadas a um projeto maior de educação republicana. O perfil de professor era primado pela administração pública, que não escondia suas reais pretensões, como mostram as declarações de Castro Pinto à revista $A$ Escola edição n ${ }^{\circ} 3$ de 1900: 
de vulgarização, no professorado paraense, que na leitura de semelhantes dissertações encontrará o melhor dos preparos teóricos para o seu patriotismo mister.

Chegamos ao nosso intuito precioso: o aperfeiçoamento do mestre, para que ele saiba nos dar discípulos perfeitos. (PINTO, A ESCOLA, 1900, p. 6).

\section{AS REVISTAS: MATERIALIDADE E IDEIAS}

Com relação à materialidade, a revista $A$ Escola, era organizada em edições mensais e individuais contendo cerca de 120 páginas. Podia ser também organizada em tomos, que nada mais eram do que compêndios encadernados que atendiam edições, bimestrais ou trimestrais, chegando a conter cerca de 600 páginas. Disposta em formato de papel $15 \times 21 \mathrm{~cm}$, esse impresso se dividia em 7 seções, assim distribuídas: Seção "Doutrina", "Contos e Biografias", "Exercícios Escolares", "Conselho Superior", "Administração", "Legislação" e "Notícias e Correspondências".

Virgílio Cardoso de Oliveira, idealizador da revista $A$ Escola, no ano de 1900, em documento especial de orientação aos professores do Pará, procurou traduzir o seu lema, "É preciso partir do mestre para o discípulo" (OLIVEIRA, $A$ ESCOLA, 1900, p. 5). Esse discurso ecoou entre as seções da revista $A$ Escola e alinhou-se às intenções da Diretoria de Ensino do Estado. A revista A Escola tinha por missão formar bons professores e seu conteúdo buscava, entre outros aspectos, ampliar o conhecimento do professorado paraense, de forma a atingir o nível de excelência para o ensino.

A seção "Doutrina" destinava-se à publicação de estudos sobre assuntos

\footnotetext{
5 Esta seção se constituía pelas correspondências dos jornais do Estado e do interior e de muitos jornais de outros estados que recebiam os exemplares da revista e enviavam nota de agradecimento à redação do impresso, enaltecendo o conteúdo abordado pela revista em suas seções. Entre os jornais do Pará, destacam-se O Ateneu, O Agrônomo, A Província do Pará, Folha do Norte, Gazeta de Alenquer, entre outros da capital e interior do Estado. Além dos jornais de outros estados como, Era Nova de Pernambuco, O Estado de Sergipe, entre outros das demais regiões do país, a redação da revista $A$ Escola, enviava ainda seus exemplares às redações de revistas de ensino e revistas científicas como, Brazil Médicos, Revista do Instituto Geográfico da Bahia, Revista Acadêmica do Rio de Janeiro, entre outros impressos.
} 
relacionados à educação primária, sendo eles originais ou transcritos de outras revistas pedagógicas do Brasil e até mesmo de publicações estrangeiras. Essa seção abria-se ainda para discussões, por exemplo, das leis do ensino, bem como para veicular os discursos realizados em eventos cívicos, como as conferencias cívicas.

A seção "Contos e Biografias" trazia novelas e histórias narradas em gênero poético, onde o espírito cativante do enredo buscava sensibilizar os corações infantis para as suas reais intenções, a lição de moralidade no ensino. A seção "Exercícios Escolares" se colocava como um espaço onde os professores tinham acesso a atividades das diversas disciplinas que compunham o programa de ensino primário, atividades que deveriam ser multiplicadas nas classes escolares.

A seção "Conselho Superior" era um espaço para a publicação das deliberações, pareceres e decisões tomadas pelo Conselho Superior de Ensino. Essa seção se solidificava com a seção "Administração", que buscava divulgar as ações da Diretoria Geral de Ensino, assim como os atos do Governo para a educação no estado. Fechando essa tríade administrativa, a seção "Legislação" servia como espaço divulgador das leis, decretos, portarias, regimento das escolas, programas de ensino e exames escolares.

A revista $A$ Escola era um impresso divulgador das ações no ensino no Pará não apenas em nível estadual, mas em âmbito nacional. Para tanto, a redação da revista fazia uso da seção "Notícias e Correspondências" para propagandear os eventos ocorridos nas instituições e institutos escolares, além de noticiar os congressos nacionais de educação, entre outros assuntos. Entre as notícias, destacavam-se as ações dos grupos escolares e escolas da capital e do interior do estado. Vale destacar que a redação da revista A Escola, encaminhava seus exemplares aos jornais do Estado do Pará, esse envio, estendia-se ainda a jornais e revistas pedagógicas e científicas de boa parte dos estados do país. Portanto, esta seção se revelava como um espaço destinado para a imprensa agradecer pelos exemplares recebidos e enaltecer o trabalho 
desenvolvido pela revista $A$ Escola.

A revista $A$ Escola tinha por objetivo direcionar as práticas dos professores paraenses, bem como divulgar os avanços educacionais estabelecidos pela política da época. Sua circulação era semanal e suas edições eram disponibilizadas ao professorado, através de assinaturas que também eram estendidas para todo o estado do Pará.

A revista $A$ Escola se colocava como um veículo de luta pelo desenvolvimento da instrução pública no Estado do Pará aos moldes republicanos, logo, procurava traduzir a marcha do ensino pós proclamação da República. Com esse propósito, procurava ser um órgão e porque não dizer uma instituição de propaganda do ensino e dos interesses da administração pública, bem como, dos professores e intelectuais que editavam seus artigos nessa revista. É importante pontuar que, os professores eram vistos por este impresso como "nobreza" que conseguiria acender a inteligência das crianças, que em muitas das vezes se apresentava de forma obscura diante do conhecimento. Assim, cabia ao professor trazer essa criança à luz que somente a boa instrução poderia dar, de forma a guiá-la na primada carreira da vida.

Quanto à circulação, a revista $A$ Escola teve uma circularidade no período de 1900 a 1905, considerado seu momento de ascendência diante do papel a que se propunha, contribuindo assim para ecoar as vozes da República para a educação no estado, constituindo-se a porta-voz da administração pública, assim como de muitos intelectuais que faziam da revista o veículo de aceitação do novo regime político.

Ao se analisar o lançamento da revista $A$ Escola e sua circularidade por cinco anos consecutivos na primeira década da República no Pará, percebeu-se que a Diretoria da Instrução Pública do Estado manteve-se firme em seus propósitos, ao fornecer a orientação moral e pedagógica aos mestres do ensino público nos anos de 1900 a 1905, período de circulação desse impresso no Pará. Contudo, na impossibilidade de se descer aos pormenores sobre o que teria motivado o silenciamento da Diretoria de Ensino no período de 1906 a 1910, no 
que diz respeito às orientações destinadas ao professorado do Pará, procurou-se aqui refletir sobre o papel, significado e as funções que os impressos pedagógicos desempenharam no ensino, como estratégia de promoção do republicanismo no Estado.

Com efeito, foram quatro anos em que não se viu a circulação de impressos pedagógicos ligados diretamente à Diretoria de Ensino do Estado, fato que nos levou a questionar o que teria motivado a extinção do impresso em 1905. O momento político pelo qual passava o estado teria influenciado a ausência de impressos ligados ao governo do Pará? Durante o levantamento dos dados não foi possível visualizar as nuanças que motivaram esse silenciamento nem a extinção do respectivo impresso.

Os questionamentos levantados levaram a buscar indícios para possíveis respostas. Nos anos de 1899 a 1910, a educação do Pará passou por certas reformulações e no período de circulação da revista $A$ Escola, a educação do estado regia-se pelas determinações do Decreto de $n^{0} 625$ de 2 de janeiro de 1899 que reorganizou o ensino primário no Pará, e posteriormente foi substituído pelo Decreto de $\mathrm{n}^{0} 1190$ de 17 de fevereiro de 1903, que reorganizou o Ensino Primário no estado.

Convém destacar que o Decreto $\mathrm{n}^{0} 625$ de 2 de janeiro de 1899 chegou a abordar como competência da Diretoria de Ensino do Estado o dever de criar uma revista destinada para a orientação dos professores. Assim, o Art. no 5 e inciso 25 desse decreto destacam que a função da Diretoria era "Providenciar sobre a publicação de uma revista do ensino tendente a promover o desenvolvimento da instrução pública do Estado e a informar os professores a respeito do progresso do ensino e reformas operadas" (PARÁ, REGULAMENTO GERAL DO ENSINO PRIMÁRIO, 1899, p. 7).

Com relação ao Decreto de $\mathrm{n}^{0} 1190$ de 17 de fevereiro de 1903, nada se observa sobre a menção de revistas destinadas a professores, fato que leva a formular a seguinte hipótese: estaria a extinção do impresso A Escola relacionada à falta de políticas que legitimassem sua importância e circulação 
no ensino?

É certo que a educação paraense passou cerca de sete anos sendo orientada pelas determinações do Decreto de $\mathrm{n}^{0}$ 1190, passando por reformulações mais amplas a partir da reforma educacional de 1910, momento quando, aparentemente, o Estado passou a olhar de forma mais singular as demandas educacionais da época, o que de alguma forma influenciou um repensar sobre impressos destinados à educação, de forma a atender as dificuldades educacionais e, ao mesmo tempo, orientar as práticas pedagógicas dos professores, além de oferecer às famílias e alunos os novos valores republicanos para o ensino público no estado.

As reformulações ocorridas na educação em 1910 influenciaram a Diretoria de Instrução Pública do Estado a lançar em 1911 a Revista do Ensino no dia 7 de setembro, sob a tutela da Secretaria do Estado do Interior, Justiça e Instrução Pública. Idealizada pelo secretário o Sr. Augusto Olympio. Tinha como redatores Flexa Ribeiro, Leopoldino Lisboa e Jurema Franco. Suas páginas traziam artigos de intelectuais das mais diversas áreas do conhecimento, entre eles, destacavam-se Acylino de Leão Rodrigues, Eustachio da Costa Rodrigues, Teodoro Braga, entre outros. Outro aspecto interessante desse impresso é que ele passa a constituir uma nova forma de impressão e divulgação de suas propostas, ao se utilizar do recurso de gravuras e fotos em suas páginas.

As páginas da Revista do Ensino permitem acompanhar como esse impresso se colocava como uma publicação oficial de divulgação das ciências, das letras e, especialmente, da pedagogia tão necessária aos professores paraenses. Sua publicação era quinzenal e a assinatura era anual, e, no estado, custava, para seus leitores, cerca de doze mil réis, sendo que, em outros estados, esse valor passava para quinze mil réis. Os professores públicos primários tinham como obrigatória a assinatura do impresso que lhes custava dez mil réis. A manutenção dessa revista é um ponto que merece atenção, considerando que a administração pública do Estado do Pará buscava o fortalecimento de suas 
ações frente aos assuntos educacionais com recursos do próprio professorado paraense, que, mais uma vez, se colocava como financiadores dessa revista pedagógica.

Faz-se necessário destacar que todo assinante da revista tinha o direito de receber o impresso encadernado em capa dura, trabalhado em percalina ${ }^{6}$. Esse exemplar encadernado só era distribuído quando alcançasse um tomo completo, composto por quatro ou cinco revistas. Seus exemplares eram comercializados na Livraria Moderna, Livraria Clássica, Loja Pará Chic, Livraria Bitencourt.

A Revista do Ensino possuía um aspecto material bem definido, organizada em cerca de 70 a 85 páginas, apresentava um sumário bem diversificado, distribuído e, muitas vezes, não definido de forma igualitária em todas edições analisadas. De um modo geral, apresentava publicações com cerca de dez a catorze seções, distribuídas em "Higiene Escolar", "Arte de Ler", "Páginas Escolhidas", "História da Terra", "Livros Escolares", "Curiosidades Científicas", "Questões de Gramática e Filosofia”, "A Instrução Pública do Estado", "Notícias Literárias", "Pelo Magistério", "Notas e Notícias", "A Vida Escolar no Estado", "A revista", "Biografias" e, por último, mas não menos importante, "Legislação do Ensino", exemplificados nas imagens a seguir:

Com relação às seções dessa revista, faz-se menção apenas às mais recorrentes que agregam a temática deste estudo. Sobre essa questão, pontua-se que a análise da materialidade desse impresso levou a perceber a grande ênfase para o conhecimento científico na composição das seções da Revista do Ensino. A seção "Higiene Escolar" e, em algumas edições, "Higiene Social", procuraram abordar orientações do conhecimento médico científico para o aperfeiçoamento das práticas escolares. A Seção "Curiosidades Científicas" também se constituía em outra seção muito recorrente entre as edições do impresso, trazendo temáticas evolutivas dos seres vivos, buscava descrever de maneira minuciosa a vida dos seres vivos.

\footnotetext{
6 Tecido utilizado para a encadernação de livros.
} 
A seção "História da Terra" é outra seção recorrente nas edições, tinha como proposta desvelar o conhecimento astronômico e geográfico aos professores paraenses. A seção "Páginas Escolhidas" se constituía como um espaço destinado aos contos e poemas. Já as seções "A Instrução Pública" e "Legislação do Ensino" se apresentavam como espaços destinados a divulgar as ações da Diretoria do Ensino frente à educação, assim traziam decretos, portarias, pareceres para a organização do ensino. As seções "Notas e Notícias" e "A vida escolar no Estado" procuravam dar destaque aos eventos e programações realizados nas instituições de ensino da capital e do interior, além de divulgarem eventos do ensino de ordem nacional.

Entre suas funções, a Revista do Ensino assumia ainda o papel publicitário na divulgação de materiais didáticos destinados ao ensino, bem como de fazer críticas a todo e qualquer livro que lhe era oferecido. Esse fato se dava com relação às obras didáticas destinadas ao ensino de leitura e gramática da escola primária. Todo livro didático ou literário era submetido à análise de seu conteúdo. A própria revista tinha em sua contracapa um espaço comparado a "comerciais" de autores e editoras.

A avaliação sobre as produções didáticas ou literárias destinadas ao ensino consistia em verificar sua consonância com o pensamento político vigente. As gravuras, por exemplo, eram avaliadas para verificar se realmente atendiam às propostas educacionais sem ferir a moralidade social e, por fim, se fazia a análise do material utilizado para a fabricação de cada obra, mantendo assim o padrão de produção. Essa apreciação era geralmente realizada pelo redator chefe, o Sr. Flexa Ribeiro e o impresso propagandeava essas obras, dando-lhes o valor necessário para o auxílio à educação, assim como em quais livrarias poderiam ser adquiridas.

As obras avaliadas pelo corpo redator da revista eram dos mais variados conteúdos. Avaliava-se livros destinados às práticas dos professores e ao uso dos alunos, além de livros para o auxílio do ensino primário e secundário, obras literárias, livros de contos, lições de gramática e ortografia, entre outros 
assuntos. Para seus autores, a divulgação de suas produções em um impresso de grande circulação no estado e fora dele enaltecia e afirmava a validade dos livros para a educação e para o mercado editorial.

A Revista do Ensino tinha por objetivo divulgar conhecimentos pedagógicos aos professores primários, bem como aperfeiçoar suas práticas educativas, contribuindo assim para a instrução pública e para o progresso da nação, destinava-se também às pessoas dedicadas aos estudos relacionados à educação.

Para os seus idealizadores, a educação era fonte vital para a formação da nacionalidade, como bem declarou seu editorial na edição de nº 02 de 1911:

(...) a Revista do Ensino vem preencher uma grave lacuna, um grande hiato no nosso sistema de educação. A seleção que presidiu à escolha dos seus colaboradores revela a preocupação com que foram organizados os moldes de tão útil publicação. O fato sumário, que vai a seguir, dá ideia do que é esse órgão oficial de propaganda pública. (PARÁ, REVISTA DO ENSINO, 1911, p. 83).

Há que se destacar que a ideia do progresso e de mundo moderno vivenciado nos anos iniciais da República paraense trouxe parâmetros para que os intelectuais viessem a pensar a educação a ser oferecida às crianças no Pará, uma educação que viesse romper com os paradigmas existentes, herdados do império, promovendo de certa forma o avanço educacional como condição para o desenvolvimento social, econômico e cultural da sociedade paraense.

A ideia de ascensão social, econômica e cultural, por meio da educação, era uma preocupação constante dos que estavam à frente da administração pública e que, por sua vez, eram também os responsáveis por direcionar o teor do que viria a ser veiculado nos impressos paraenses. Cabe ressaltar que tanto as edições analisadas da revista $A$ Escola, quanto as edições da Revista do Ensino, trazem frequentemente em seus artigos as preocupações associadas ao êxito social por intermédio da educação. 
Portanto, o contexto e os propósitos em que foram criadas a revista $A$ Escola e Revista do Ensino foram os mais diversos, tornando-se canais de propagação dos discursos do Estado, como forma de moldar corações e mentes de professores e alunos. Sendo assim, pontua-se sobre o que, de fato, movia a Diretoria de Instrução do Estado do Pará para manter o alinhamento das orientações aos professores do Estado.

\section{CONSIDERAÇÕES FINAIS}

Este estudo toma a imprensa pedagógica como instituição de formação de mentes e práticas dos professores paraenses para o fortalecimento da política republicana no Estado. As revistas A Escola e Revista do Ensino atuaram como mecanismos de vigilância e controle das práticas existentes na educação primária no Pará, além de serem exímias difusoras de uma pedagogia cívica.

Os impressos pedagógicos se constituem em fontes de grande valor histórico na medida em que permitem entender seus usos e destinos, bem como as práticas e teorias educacionais que circulavam no material produzido pelos intelectuais que escreviam para essas revistas no Pará, fazendo circular modelos educativos com o intuito de propagar o ideário político republicano no estado. Muitos desses homens atuavam como críticos culturais e viam na imprensa pedagógica um meio de propagarem a ideia de que o país vivia uma crise moral e intelectual, que precisava ser combatida.

A República traçou caminhos para o progresso e concedeu à educação a função do remodelamento de práticas e hábitos sociais, redefinindo o processo formativo dos professores primários e suas ações educativas para serem arautos de seu ideário progressista e nacionalista. A identidade nacional, nutrida pela tônica do discurso nacionalista republicano, buscou moldar a educação no Estado, por meio de uma educação cívica, norteada pelo civismo e moralismo patriótico que orientaria os saberes e as práticas dos professores. 
A força da imprensa pedagógica traduzia-se em discursos de literatos, médicos, professores e personalidades da administração pública do Estado, que, por meio de suas produções, institucionalizaram na educação e no ensino no Pará uma "escrita autorizada do Estado", que, na concepção de Chartier (2002), determina o que deveria ser seguido pelo ensino, logo, a ordem do discurso desses homens do republicanismo paraense era o estabelecimento de um "prontuário", termo utilizado por Gondra (2004), constituído pelas prescrições necessárias para a reforma social, via educação.

Acredita-se ser possível afirmar que o papel desempenhado pela imprensa pedagógica no Pará foi algo preponderante no que tange aos avanços alcançados na educação do Estado, uma educação que crescia e se fazia ver pelas páginas das revistas A Escola e Revista de Ensino. Essas revistas se constituíram em mecanismos decisivos na veiculação de orientações sobre os programas de ensino, conteúdos, métodos, notas, sobre o ensino na capital e no interior, uso de livros escolares, exames, festas escolares, conferências cívicas, poesias, hinos, legislação educacional, pronunciamentos da diretoria da instrução pública, relatório dos diretores dos grupos escolares da capital e do interior, além de artigos dos mais variados assuntos que discutiam a educação paraense e suas práticas. Interessante notar também que esse fluxo de conteúdos e ideias republicanistas moldariam as práticas dos professores e os perfis das crianças que representariam o futuro da nação que se construía.

Pode-se destacar que as análises das revistas A Escola e Revista do Ensino, evidenciaram, entre outros aspectos, o papel da imprensa pedagógica no Pará como espaço de formação de professores e de reforma social por meio da educação. Nesse sentido, a missão de propagar as prescrições do saber pedagógico necessário para o exercício de um bom ensino fez desses impressos arautos da proposta de educação republicana no Pará. Ao se colocarem como uma escrita de Estado e instituições formadoras de identidades, construíam uma rede de representações discursivas, que se validaram pelo papel oficial que assumiam, com relação às práticas do professor primário. 
Entende-se ser a imprensa de educação e ensino no Pará republicano uma marca privilegiada de uma história, de um espaço impresso instituído como polo de referência na formação do professorado paraense, da propagação da cultura e do saber pedagógico para os padrões republicanistas.

Procurou-se demonstrar ao longo deste trabalho que as questões sobre a imprensa pedagógica no Pará estão longe de serem finalizadas. Contudo, este texto revela o posicionamento da revista A Escola e da Revista do Ensino sobre educação, ciências e letras na formação do cidadão republicano. Revistas que nasceram e assentaram-se no estado como um apoio à educação pública almejada. Nelas, é perceptível a preocupação dos intelectuais com a formação moral e patriótica do cidadão republicano.

\section{REFERÊNCIAS}

BASTOS, Maria Helena Camara. A imprensa periódica educacional no Brasil: de 1808 a 1944. In: CATANI, Denice Barbara; BASTOS, Maria Helena Câmara (org.). Educação em Revista: a imprensa periódica e a história da educação. São Paulo: Escrituras, 2002. p. 173-187.

CHARTIER, Roger. A história cultural: entre práticas e representações. Tradução Maria Manuela Galhardo. $2^{\mathrm{a}}$ ed. Rio de Janeiro: Difel, 2002.

CHARTIER, Roger. O mundo como representações. Estudos Avançados, vol 5, No 11, jan/abr. 1991, p 173-191. Disponível em <http://www.revistas.usp.br/eav/article/view/8601> Acesso em: 30 abril 2018.

COELHO, Geraldo Mártires. Na Belém da Belle Époque da borracha (1890-1910): dirigindo olhares. Revista Escritos (Revista da Fundação Casa de Rui Barbosa), Ano 5, $\mathrm{N}^{\circ}$ 5, 2011. p. 141-168.

COELHO, Maricilde Oliveira. A escola primária no Estado do Pará (19201940). Tese - (Doutorado em Educação) - Universidade de São Paulo. Programa de Pós-Graduação em Educação, São Paulo, 2008.

COSTA, Rafaela Paiva. A formação de professores da Primeira República no Pará (1900-1904). Dissertação - (Mestrado em Educação). Universidade Federal do Pará. Programa de Pós-Graduação, Instituto de 
Ciências da Educação, Belém, 2011.

GONDRA, José Gonçalves. Artes de civilizar: medicina, higienismo e educação escolar na corte imperial. Rio de Janeiro: Eduerj, 2004.

FERNANDES, Ana Lúcia Cunha. O impresso e a circulação de saberes pedagógicos: apontamentos sobre a imprensa pedagógica na história da educação. In: MAGALDI, Ana Maria B. M.; XAVIER, Libânia Nacif. Impressos e história da educação: usos e destinos. Rio de Janeiro: 7 Letras, 2008, p. 15-29.

NÓVOA, Antônio. BANDEIRA. Filomena. PAULO, João Carlos. TEIXEIRA, Vera. A imprensa de educação e ensino: Concepção e organização do repertório português. In: CATANI. Denice Barbara; BASTOS. Maria Helena Câmara (orgs.). Educação em Revista. São Paulo: Escrituras, 2002, p. 11-31.

SARGES, Maria de Nazaré. Belém: riquezas produzindo a Belle Époque (1870-1912). 3. ed. - Belém/PA, Editora: Paka-Tatu, 2010.

SEVCENKO, Nicolau. Literatura como missão: tensões sociais e criação cultural na Primeira República. 2. ed. São Paulo: Companhia das Letras, 2003.

SOUZA, Rosa Fátima de. Alicerces da Pátria: História da escola primária no Estado de São Paulo (1890-1976). Campinas, SP: Mercado de Letras, 2009.

\section{FONTES}

PARÁ. Governo do Estado do. A Escola, nº 01: Imprensa Oficial, Pará, 1900. PARÁ. Governo do Estado do. A Escola, nº 03: Imprensa Oficial, Pará, 1900. PARÁ, Governo do Estado do. A Escola, no 42: Imprensa Oficial, Pará, 1903. PARÁ, Governo do Estado do. A Escola, no 45: Imprensa Oficial, Pará, 1904. PARÁ, Governo do Estado do. A Escola, no 46: Imprensa Oficial, Pará, 1904. PARÁ, Governo do Estado do. Revista do Ensino, no 2 : Imprensa Oficial, Pará, 1911.

PARÁ, Governo do Estado do. Revista do Ensino, no ${ }^{\circ}$ : Imprensa Oficial, Pará, 1912. 
PARÁ, Governo do Estado do. Decreto no 850 de 30 de abril de 190o, que torna obrigatória a assinatura da revista $A$ Escola para os professores primários do Estado. Pará - Brasil: Tipografia do Instituto Lauro Sodré, 1900.

PARÁ, Governo do Estado do. Regulamento Geral da Instrução Pública reorganizado pelo Decreto no. 625 de 2 de janeiro de 1899. Pará Brasil: Tipografia do Diário Oficial, 1889.

PARÁ, Relatório referente ao ano de 1899, apresentado ao Exmo Sr. José Paes de Carvalho, governador do Estado. Pará - Brasil: Tipografia do. Instituto Lauro Sodré, 1899.

PARÁ, Notas e Notícias. Revista do Ensino do Pará, nº 2: Imprensa Oficial, Pará, 1911, p. 82-83.

PARÁ, Governo do Estado do. Decreto No 1190 de 1903, regulamentado pelo governador do Estado, o Exmo. Sr. Augusto Montenegro em 1903. Pará - Brasil: Tipografia do Instituto Lauro Sodré, 1903.

PINHEIRO, Conego Andrade. Educação. A Escola, no 46: Imprensa Oficial, Pará,1904, p. 119-125.

PINTO, Castro. A Escola. A Escola, nº 03: Imprensa Oficial, Pará, 1900, p. 3-6.

OLIVEIRA, Virgílio Cardoso. Discurso. A Escola, $\mathrm{n}^{0}$ 01: Imprensa Oficial, Pará, 1900, p. 7-18.

OLIVEIRA, Virgílio Cardoso de. Discurso. $2^{\mathbf{a}}$ Conferência Cívica. Edição Especial para Escolas: Imprensa Oficial, Pará, 1900.

DARLENE MONTEIRO DOS SANTOS é Mestre em Educação, na linha de Saberes Culturais e Educação na Amazônia - PPGED - UEPA . Especialista em Educação da Secretaria de Estado de Educação do Pará - SEDUC/PA e docente da Secretaria Municipal de Educação de Belém - SEMEC. Pesquisadora do Grupo de Pesquisa História da Educação na Amazônia (GHEDA).

E-mail: Darlene.monte@hotmail.com

(b) http://orcid.org/0000-0001-7569-7592 
MARIA DO PERPÉTUO SOCORRO GOMES DE SOUZA AVELINO DE FRANÇA é Doutora em História, Filosofia e Educação pela Universidade Estadual de Campinas e Pós Doutorado em História da Educação pela Pontifícia Universidade Católica do Rio Grande do Sul. Professora Adjunta do Curso de Pedagogia e do Programa de Pós Graduação da Universidade do Estado do Pará. Coordenadora do Grupo de Pesquisa História da Educação na Amazônia (GHEDA).

E-mail: socorroavelino@hotmail.com

(D) http://orcid.org/0000-0002-6974-2606

Recebido em: 06 de maio de 2019

Aprovado em: 21 de setembro de 2019 